cyst on account of the inability to destroy the interior of the cyst. It seems probable, however, that the desired result has been accomplished by the thorough application of the actual cautery to the inner cyst wall, thereby substantiating the supposition of Dr. Peaslee, on page 221 of his work, that the operation of Noeggerath might be made applicable to cases of dermoid cyst of the ovary.

\title{
TWO CASES OF CHOREA IN THE KITTEN, WITH AUTOP- SIES.
}

BY JAMES J. PUTNAM, M. D.

Through the courtesy of Mr. D. G. Wilkins I have recently been able to examine the central nervous system of two kittens that almost from their birth had suffered from chorea of the most typical kind. Two others from the same litter had also had the disease, but had been killed. All four, as well as two more that were unaffected, were healthy-looking, well-developed, playful animals, as their mother had been before them. The symptoms were first noticed almost if not quite as soon as the movements of the little creatures began to attract attention at all, and rather increased than diminished in intensity with advancing age. No post-natal cause could be assigned, except that the cellar in which they were born was somewhat damp. The only respect in which the symptoms differed in any way from the classical symptoms of human chorea was that when the kittens (this was true at least of one of them) were held carefully in the arms and caressed, the involuntary movements sometimes ceased for a few minutes. Even the movements of choreic children, however, often diminish greatly under similar conditions. In connection with the least voluntary effurt, even that of standing, the picture became characteristic and striking. An unseen tormentor seemed to be making sport of the little beasts. A leg on which one of them was standing, or which it was using in play, would be suddenly twitched a little to one side or backwards; or, while rumning forward, the animal would suddenly pause and balance backward, even falling on its haunches, as if pulled back by the tail; or it would be thrown suddenly on its side to the ground. The tail and the muscles of the face and of the whiskers were involved, and often the hair all over the body was more or less erected, giving the skin a tumbled look, as if the animal had recently received a ducking. The heart was not auscultated.

One of the animals was killed when about one month old, the other a few weeks later. In the case of the former the spinal cord was first divided, under ether, in the dorsal region, to see if the movements persisted, as Chauveau has said of the dog, for the parts behind the section. 
The kitten was allowed to recover fully from the ether, and was shortly afterwards killed, no choreic movements having shown themselves, either spontaneously or in connection with the reflex contractions which were readily excited in the hind legs. Possibly they might have appeared had a longer time been allowed to elapse. The hearts of both kittens were carefully examined for endocarditis, but none was present. The cords and brains were hardened in Müller's fluid. Subsequent microscopic examination failed to reveal any abnormal changes in the brain, cerebellum, medulla oblongata, or cord of either case. It was not thought necessary to examine the entire specimen piecemeal ; sections were made from many parts of the cord and brain, including the cerebral ganglia and parietal cortex and the cerebellum. In the younger kitten the blood-vessels were everywhere injected, often crowded with blood, but there was no trace of the escape of leucocytes, as described by Drs. Gowers and Sankey in their interesting paper upon the Pathological Anatomy of Canine Chorea. ${ }^{1}$ It was thought possible that this injection, which was mainly confined to the capillaries and veins, had been due to the effects of the operation on the spinal cord, combined with the struggles of the animal at the moment of death, which was brought about by hyper-etherization in an air-tight jar.

The blood-vessels of the other kitten, however, which was killed in the same way, were not even injected, except slightly here and there, as under normal conditions. The ganglion cells in the spinal cord, as well as those in the brain, of the younger kitten - that in which the injection was observed - failed to imbibe the staining fluids, and even in glycerine they could not be satisfactorily studied. Nothing, however, could be more perfectly healthy to all appearance than the ganglion cells in the case of the second, the older kitten, both in all parts of the spinal cord, the medulla oblongata, the cerebellum, and the brain. Nothing suggesting embolism could be found in either case.

It is plain that the pathological lesion of animal as well as of human chorea, if, indeed, there is any single, characteristic lesion, has yet to be discovered. In one of the cases of Gowers and Sankey extensive changes were indeed present, in the form, mainly, of deposits or extravasations of lymphoid cells, widely disseminated through the central nervous system, and associated with alterations in the nerve elements. In this case, however, the symptoms, especially the presence of profound cutaneous anæsthesia, suggest that something more than simple chorea had been active as a cause. In the other case certain changes were seen in the ganglion cells of the cord, but their interpretation is made more difficult by the fact they were more widely disseminated than the distribution of the symptoms, which were confined to one fore leg, would seem to warrant.

1 Medico-Chirnrgical Transactions, vol.lx. 
It is probable that we shall have to acquire more exact a priori notions respecting the physiology of the nervous centres, as, for example, through such researches as those of Hughlings Jackson, before we can succeed in turning these discrepant pathological observations to good account.

\section{RECENT PROGRESS IN OPHTHALMOLOGY.}

BY O. F. WADSWORTH, M. D.

Theory and Treatment of Glaucoma. - In an article on iridectomy and sclerotomy in glaucoma, ${ }^{1}$ Mauthner put the question whether, in glaucoma simplex and chronic inflammatory glaucoma, when an individual is still capable of work, although central or peripheral vision, or both, have suffered severely, it is allowable to subject him to an operation (iridectomy) which may lead quickly to destruction of sight. $\mathrm{He}$ returns to the subject, ${ }^{2}$ and answers the question in the negative, rejecting iridectomy absolutely in many cases in favor of sclerotomy. There is no attempt to support any theory of the action of sclerotomy ; indeed, he avows that he understands the action of the one operation as little as of the other; but the opinion is based on his own experience, since he has not seen such bad results after scleròtomy as after iridectomy.

The immediate bad results after iridectomy may be attributed either to the disease itself, independently of the operation; to the optical effect of the operation, the coloboma causing a diminution of vision, specially marked when astigmatism, regular or irregular, existed previously or has been caused by the wound, incarceration of iris, etc.; or, finally, to a harmful effect of the operation on the course of the disease.

Of seventeen eyes affected with chronic glaucoma, mostly glaucoma simplex, and which possessed vision before operation, in only three was vision improved by iridectomy; in five it remained stationary, but in three of these only by the help of cylinder glasses or tattooing; while in eight it was lessened, and in five of these eight cases vision that had enabled the patients to work was rendered useless. In all the iridectomy was done upward. Nor did the decrease of vision depend on non-effect of the operation in reducing tension, for in only one of the cases tension remained high.

The poor results obtained from iridectomy led to the empirical trial of sclerotomy. There was sufficient encouragement in the facts that no satisfactory explanation of the benefit of excision of the iris has been given, and that many cases have been observed in which a very far from properly performed excision has sufficed to cure glaucoma, - even an excision only of a bit of the sphincter, or of the periphery with the

1 Wiener med. Wochenschrift, 27-30, 1877.

2 Archives of Ophthalmology and Otology, vii. 179. 